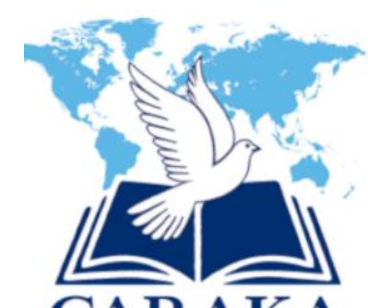

\title{
Implikasi Kekudusan Seksualitas Terhadap Hubungan Manusia Dengan Allah
}

\author{
Angilata Kebenaran Halawa, Firman Panjaitan \\ Sekolah Tinggi Teologi Tawangmangu \\ Angilatahalawa@gmail.com \\ Panjaitan.Firman@gmail.com
}

\begin{abstract}
God is the creator who gives life and everything in this world is the result of His creation, including the issue of sexuality. Sexuality is a very important thing to consider. Because in the beginning, God created man to be very good. In this modern era, most people fail in the problem of sexuality, because they can not restrain themselves and are caused by promiscuity. Then what should be done? In this study, the author will try to explain how important sexuality and His relationship with a holy God are. If God is holy, then sexuality must also be holy and has been blessed by God through God's servants. Through this research, everyone can appreciate sexuality as sacred before God.
\end{abstract}

Keywords: God; God's holiness; Sexuality; The Holiness of Sexuality

\begin{abstract}
Abstrak
Allah adalah pencipta yang memberi kehidupan dan segala sesuatu di dunia ini adalah hasil ciptaan-Nya, termasuk masalah seksualitas. Seksualitas adalah hal yang sangat penting untuk dipertimbangkan. Oleh karena pada mulanya, Tuhan menciptakan manusia dengan sangat baik. Di era modern ini, kebanyakan orang gagal dalam hal seksualitas, karena tidak bisa menahan diri dan disebabkan oleh pergaulan bebas. Jika demikian halnya, apa yang harus dilakukan? Dalam penelitian ini, penulis akan mencoba menjelaskan betapa pentingnya seksualitas dan hubungan-Nya dengan Tuhan yang kudus. Jika Tuhan itu kudus, maka seksualitas juga harus kudus dan telah diberkati Tuhan melalui hamba-hamba Tuhan. Melalui penelitian ini, setiap orang dapat menghargai seksualitas sebagai yang kudus dihadapan Allah.
\end{abstract}

Kata Kunci: Allah; Kekudusan Allah; Seksualitas; Kekudusan Seksualitas 


\section{PENDAHULUAN}

Pengertian kekudusan yang digunakan dalam Perjanjian Lama biasanya menggunakan kata qadesy "kekudusan", sedangkan sejak awal kata yang digunakan adalah qadosy yang berarti dipisahkan atau dikhususkan dengan maksud keagamaan. ${ }^{1}$ Penjelasan mengenai kata qados dalam Perjanjian Lama mempunyai beberapa bentuk. Kekudusan dalam bentuk kata sifat memiliki pengertian kudus yang mempunyai keterpisahan dari terang yang terpisah dari gelap yang menyangkut tentang pribadi yang kudus dengan Tuhan. Sedangkan kata kerjanya menggunakan kata "menguduskan" yang mana Allah sendiri menunjukkan kekudusan-Nya. Agus Prayitno menerangkan bahwa kata kerja kudus yang merupakan pengabdian, bukan dengan implikasi sementara, tapi memindahkan kepada posisi kesalehan, yang berarti pengabdian seseorang bukan bersifat eksklusif. Fokus dari peran pengabdian ini merupakan perbuatan untuk menghormati kekudusan Allah (Bil. 20:12) yang dipisahkan untuk maksud ketuhanan. $^{2}$

Kekudusan dalam Perjanjian Lama memiliki kaitan yang erat dengan umat pilihan-Nya yaitu bangsa Israel. Pemilihan/perjanjian adalah ungkapan unik tentang kekudusan Allah. Oleh karena Allah kudus maka Allah juga menuntut umat-Nya untuk hidup kudus (Im 11:44). Pada hakikatnya Allah yang kudus mengajak umat-Nya untuk menjadi kudus. Dalam Perjanjian Lama khususnya pada bagian nabi-nabi menjelaskan bahwa Allah menunjukkan kekudusanNya bagi makhluk ciptaannya, namun Allah juga menuntut kesucian dari umatNya. ${ }^{3}$ Perjanjian Lama membahas kekudusan dalam berbagai hal. Pada tulisan ini penulis akan berfokus kepada kekudusan seksual. Kekudusan seksual pada umumnya dipandang sebagai hubungan antar manusia atau suami isteri sebagai kesatuan yang telah diberkati dan menjadi kudus. Berbeda dengan pembahasan kali ini yang lebih merujuk kepada implikasi kekudusan seksual antara manusia dan kaitannya dengan kekudusan Allah.

\section{METODE PENELITIAN}

Dalam penelitian ini, penulis menggunakan metode library research (penelitian kepustakaan) dengan mengumpulkan data dari berbagai literatur, buku-buku dan jurnal-jurnal hasil penelitian sebelumnya. ${ }^{4}$ Dalam penelitian ini, penulis akan membahas mengenai

${ }^{1}$ Lasor W.S dkk., Pengantar Perjanjian Lama 1 (Jakarta: BPK Gunung Mulia, 2008), 215.

${ }^{2}$ Agus Prayitno, "Pemahaman Pembangunan Doktrin Kekudusan Allah Bagi Mahasiswa Teologi" (2011): 62 .

${ }^{3}$ Ibid, 64

${ }^{4}$ Poppy Yaniawati, "Penelitian Studi Kepustakaan," Penelitian Kepustakaan (library research), no. April (2020): 11.

176 | Copyright@ 2021, CARAKA, ISSN 2722-1407 (Cetak), 2722-1393 (Online) 
seksualitas serta hubungannya dengan Allah yang kudus. Kekudusan Allah dan kekudusan seksualitas menjadi pokok dalam penelitian ini.

\section{HASIL DAN PEMBAHASAN}

\section{Kekudusan dalam Perjanjian Lama}

Kekudusan adalah salah satu dari sifat utama Tuhan yang menjadi ciri khasNya. Kekudusan adalah kasih yang sempurna sehingga kekudusan dan kasih adalah suatu yang tidak terpisahkan, sebab Tuhan adalah kudus. Penjelasan lain mengatakan bahwa akar kata qados kemungkinan tidak berasal dari Ibrani melainkan tradisi Kanaan yang kemudian diambil alih oleh agama-agama sekitar. Dalam bahasa Ibrani asli yang dekat dengan kata kudus yaitu haram yang artinya "dari apa yang dilarang". Kudus mengandung arti tentang lingkaran suci/keramat, terang dan terpisah dari hal yang kotor. Qados merupakan suatu kualitas yang digunakan untuk Tuhan atau memuji Tuhan (Yes. 53:13). Qados menyangkut tentang pribadi yang kudus, pikiran, tempat, atau waktu yang diabadikan untuk Tuhan. Qados juga mengacu kepada pribadi Tuhan (Kel.15:11) baik rohNya, namaNya, perbuatanNya (Yes. 52:10), jalanNya (Maz. 77:1), juga mengacu kepada manusia, imam (Im. 21:6), objek persembahan (Kel. 29:33) dan persembahan (Kel. 28:38). ${ }^{5}$ Menurut Willem A. Van Gemeran, kata kerja kudus ini merupakan pengabdian, bukan dengan implikasi ibadah sementara, tapi memindahkan kepada posisi kesalehan, yang mana pengabdian seseorang bukan untuk yang bersifat eksklusif. Fokus dari proses pengabdian ini merupakan perbuatan untuk menghormati kekudusan Allah (Bil. 20:12) yang dipisahkan untuk maksud keTuhanan. Konsep kekudusan merupakan satu tema yang penting dalam sejarah Israel sebagai bangsa pilihan Allah. Konsep kekudusan ini dimulai dan ditandai dalam suatu hubungan kasih yang dikenal dengan perjanjian. Kekudusan hidup, harus ditampakkan oleh orang Israel dalam keseluruhan hidup mereka dengan menaati segala perintah dan melaksanakan berbagai perintah yang ditetapkan oleh Tuhan, Allah mereka.

Secara khusus dalam tulisan Thomas Aquinas, menjelaskan bahwa sekalipun demikian pembenaran dan pengudusan tidaklah dibedakan dengan jelas. Pembenaran dan pengudusan termasuk dalam infusi anugerah Ilahi, sebagai sesuatu yang substansial ke dalam jiwa manusia. Melalui anugerah ini, jiwa manusia diangkat menuju satu tingkatan baru yang lebih tinggi atau dalam kedudukan yang lebih tinggi, dan jiwa tersebut dimampukan untuk dapat

${ }^{5}$ Willem A. Van Gemeran, New International Dictionary of the old testament theology \& exegesis Vol.3, (America : Paternoster Press, 2002), 879.

177 | Copyright@ 2021, CARAKA, ISSN 2722-1407 (Cetak), 2722-1393 (Online) 
memperoleh tujuan surgawi untuk dapat mengenal, memiliki dan menikmati hubungan dengan Allah. Menurut Thomas Aquinas, apabila dilihat dari sisi Allah maka anugerah yang menguduskan dalam jiwa memastikan adanya remisi bagi dosa asal (original sin), lalu menanamkan kebiasaan yang menetap dari kebenaran batiniah dan membawa potensi untuk berkembang lebih lanjut dan dapat mencapai kesempurnaan. Dari hidup yang baru tersebut, muncullah segala kebaikan-kebaikan. Kemudian, dari sisi manusia, karya supernatural dari iman yang bekerja melalui kasih telah mencapai jasa di hadapan Tuhan, dan memastikan akan adanya anugerah yang makin meningkat. Pekerjaan seperti itu sangat tidak mungkin tanpa adanya karya anugerah Allah yang terus menerus. ${ }^{6}$

\section{Qadesh dan Qadeshah}

Salah satu hal yang paling unik tentang pengertian kudus ialah beberapa merujuk kepada kata pelacur atau pemburit. Pada dasarnya, kata kudus ini berasal dari budaya Kanaan yang digunakan oleh bangsa Israel sebagai suatu sifat Allah yang mereka anggap adalah kudus dan yang layak disembah. Pengertian mengenai kudus menjadi polemik dan susah untuk dimengerti oleh sebagian orang. Oleh karena kata kudus yang digunakan oleh umat Israel pada dasarnya ialah keterpisahan dari terang yang terpisah dari gelap yang menyangkut tentang pribadi yang kudus dengan Tuhan. Jika hal ini dilihat dari sejarah, penggunakan kata ini terdapat dalam kuil-kuil penyembahan agama-agama Kanaan yaitu kata qadesh (pelacur kuil atau merujuk kepada laki-laki) dan qadeshah (pecalur kuil yang merujuk kepada perempuan). Salah satunya ialah dalam 1 Raja-raja 22:47 terjemahan LAI dan TB "Dan sisa pelacuran bakti yang masih tinggal dalam zaman Asa, ayahnya, dihapuskannya negeri itu" dalam KJV "And the remnant of the sodomites, which remained in the days of his father Asa, he took out of the land (1 Ki. 22:46 KJV). Kata "pelacuran bakti" menggunakan kata "the

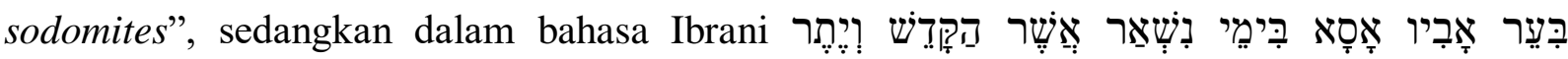

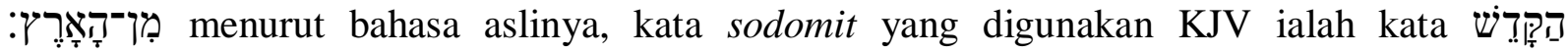
(semburit bakti itu). Oleh sebab itu, para pelacur yang ada di kuil-kuil tersebut disebut sebagai qadesh dan qadeshah. Lebih jelasnya dikatakan oleh Asnath bahwa mereka adalah "pelacur kultus", yang merupakan pelacur yang mempersembahkan hidup mereka bagi ritual keagamaan. $^{7}$

\footnotetext{
${ }^{6}$ Louis Berkhof, Teologi Sistematika Jilid 4 (Surabaya: Momentum, 2001), 275.
}

7 Asnath N Natar, "Perempuan Dalam Kitab Hosea" (n.d.). 139. 178 | Copyright $\odot$ 2021, CARAKA, ISSN 2722-1407 (Cetak), 2722-1393 (Online) 
Agama Kanaan adalah agama kesuburan, sebab baal adalah dewa utama orang-orang Kanaan yang memiliki arti nama pemilik atau tuan. Sejarah mitologi orang Kanaan menganggap bahwa Baal adalah puta El, dewa utama dan Asherah, dewi laut. Mereka menyembah Baal sebagai dewa kesuburan yang menyediakan panen melimpah dan juga yang memberikan kesuburan dalam hal untuk menghasilkan anak-anak. Pemujaan baal ini berakar pada sensualitas dan melibatkan pelacuran ritualistik di kuil-kuil. Sensualitas yang dimaksud merujuk kepada segala sesuatu mengenai badani dan bukan rohani. Pada dasarnya, orangorang Kanaan adalah para petani, sehingga mereka percaya bahwa asal dari kesuburan negeri tersebut adalah pekerjaan yang dilakukan oleh dewa Baal mereka. ${ }^{8}$

Dengan demikian, penulis dapat menyimpulkan bahwa sejarah penggunaan kata kudus yang sekarang diberikan kepada Allah yang adalah kudus berasal dari budaya Kanaan dan dikenakan kepada mereka yang adalah para pelacur bakti, yang mana perempuan sebagai pelacur bertugas untuk melayani para laki-laki secara biologis dan pemburit dikenakan kepada laki-laki yang bertugas untuk melayani para perempuan. Tindakan pelacuran bakti ini bertujuan untuk melakukan hubungan seksual sebagai bentuk penyembahan mereka dan penghormatan kepada baal yang mereka sembah yang akan memberikan mereka kesuburan tanah maupun dapat memberikan anak. Oleh sebab itu, orang Israel mengadopsi kata tersebut yaitu qadesy "kekudusan" dan dikenakan kepada Allah yang adalah kudus dan tidak bercela yang menuntut umat agar hidup kudus seperti Dia, yang layak dihormati dan disembah oleh segenap umat Israel.

\section{Kekudusan Seksualitas}

Seksualitas adalah tentang bagaimana seseorang mengalami, atau menghayati dan mengekspresikan diri sebagai makhluk seksual, dengan kata lain tentang bagaimana seseorang berpikir, merasa dan bertindak berdasarkan posisinya sebagai makhluk seksual. Hubungan seks hanyalah salah satu aspek. Seksualitas mencakup banyak hal diluar itu, segala sesuatu yang ada kaitannya dengan seks (ada kaitan dengan kelamin). Seks adalah kebutuhan alamiah pada setiap manusia. ${ }^{9}$ Seksualitas menyangkut berbagai dimensi yang sangat luas, yaitu dimensi biologis, sosial, psikologis, dan kultural. Seksualitas dari dimensi biologis berkaitan dengan organ reproduksi dan alat kelamin, termasuk bagaimana menjaga kesehatan dan

\footnotetext{
${ }^{8}$ Gandi Wibowo, “Asimilasi Dan Akulturasi Penyembahan Baal Di Bangsa Israel: Pendekatan Sosio Teologis Menurut Teori Multi Stage Asssimilation Milton M. Gordon," Voice 1, no. 1 (2021): 18.

${ }^{9}$ Linda Suwarni, "Hubungan Antara Lovestyle, Sexual Attitudes , Gender Attitude Dengan Perilaku Seks Pra-Nikah," no. 111 (2012), 28.
}

179 | Copyright $@$ 2021, CARAKA, ISSN 2722-1407 (Cetak), 2722-1393 (Online) 
memfungsikan secara optimal organ reproduksi dan dorongan seksual. Seksualitas dari dimensi psikologis erat kaitannya dengan bagaimana menjalankan fungsi sebagai makhluk seksual, identitas peran atau jenis, serta bagaimana dinamika aspek-aspek psikologis (kognisi, emosi, motivasi, perilaku) terhadap seksualitas itu sendiri. ${ }^{10}$

Pada awal proses penciptaan, dengan jelas Tuhan menyatakan, "Tidak baik, kalau manusia itu seorang diri saja. Aku akan menjadikan penolong baginya, yang sepadan dengan dia" (Kej. 2:18). Kesendirian, menurut Allah, "tidak baik". Sebab kesendirian akan menciptakan ketidak-berdayaan. Ketidakberdayaan yang hanya dapat diatasi dengan kehadiran seorang "penolong yang sepadan". Itulah beberapa penjelasan hakikat serta fungsi seksualitas itu. Seksualitas memungkinkan mutualitas atau hubungan timbal balik antar manusia, juga kesetaraan antar manusia. Selain itu, yang perlu diperhatikan adalah kesatuannya! "Inilah dia tulang dari tulangku dan daging dari dagingku. Sebab itu seorang laki-laki akan meninggalkan ayahnya dan ibunya dan bersatu dengan isterinya, sehingga keduanya menjadi satu daging" (Kej. 2:23-24). ${ }^{11}$

Dalam kitab Kejadian 1 dan 2, dalam pasal ini Tuhan memerintahkan perkawinan dan meresmikan perkawinan (Kej. 1:27-28). Allah memberkati manusia untuk bertambah banyak dan melestarikan setiap pemberian Allah atas manusia. Penyatuan pria dan wanita dalam pernikahan merupakan cara meneladani anugerah Allah dengan memenuhi perintah bertambah banyak di bumi. Seks hanya dapat dilakukan dalam pernikahan. Sehingga dalam penyatuan manusia memerlukan perhatian tahap-tahap yang Allah kehendaki. Kemudian, dalam Kejadian 2:18-25 memperlihatkan bahwa pernikahan diciptakan agar laki-laki memiliki penolong yang sepadan bagi laki-laki dan perempuan. Pembahasan seksual dalam kitab Kejadian memperlihatkan bagaimana seharusnya seorang Kristen mampu memahami maksud tujuan Allah akan penciptaan manusia di muka bumi melalui pernikahan menjadi suatu lembaga yang dianugerahkan Allah.

Dalam terjemahan WTT ברָּרך manusia berlutut dan mengadahkan tangan tanda manusia menerima berkat dari Allah dan diberikan tanggung jawab untuk bertambah banyak. Allah melengkapi manusia dengan organ seks dan dorongan seksual. Senada dengan itu dituliskan oleh John White, bahwa: “Allah juga melengkapi tubuh dengan sistem saraf yang diprogram sedemikian rupa sehingga setiap orang dapat mengalami kenikmatan yang luar biasa,yaitu kenikmatan yang kelak akan tercipta bila Kristus hadir dalam pernikahan dua orang yang

\footnotetext{
${ }^{10}$ Baran Rante Payung, Katekisasi Pernikahan dalam Gereja, ”(n.d.), 3.

${ }^{11}$ Made Nopa Setiadi, Immorality: Sebuah Studi Biblika-Sistematis (Bengkulu: Permata Raflesia, 2020), 21.
}

180 | Copyright $\odot$ 2021, CARAKA, ISSN 2722-1407 (Cetak), 2722-1393 (Online) 
saling mencintai”. Jauh sebelum manusia diciptakan Allah telah merancang seks bagi manusia. Pada prinsipnya Allah berkenan dan merestui adanya hubungan seks di antara lakilaki dan perempuan. Allah memiliki tujuan mulia menciptakan seks kepada manusia supaya manusia tertarik terhadap lawan jenis, seks diberikan untuk kelangsungan hidup manusia dan Allah memberikan seks kepada laki-laki dan perempuan sebagai suatu cara untuk menyatakan cinta kasih mereka yang total dan dalam satu terhadap yang lainnya. Oleh sebab itu, seks adalah anugrah Allah yang teramat baik untuk dinikmati oleh pasangan laki-laki dan perempuan yang telah dipersatukan dalam pernikahan kudus. ${ }^{12}$

Seksualitas adalah suatu hal yang baik diberikan Allah kepada manusia (anugerah). Jarot Wijanarko mengatakan bahwa setelah Tuhan menciptakan manusia, sebagaimana manusia itu ada, termasuk organ dan hormon seksualnya, dorongan seksualnya dan kemampuan untuk berkembangbiak, maka Tuhan berfirman, bahwa semua itu baik. Seks adalah kudus, bahkan itu perintah Tuhan. Seks bukan sesuatu yang masuk ke dalam manusia setelah manusia jatuh dalam dosa, bukan, seks yang ada dalam diri manusia adalah karya Tuhan. Seks adalah hal yang terindah, mempesona dan menyenangkan bagi setiap orang yang telah berhak menikmatinya. Hanya saja, tindakan seks yang dilakukan di luar pernikahan kudus atau dengan pasangan yang tidak sah adalah perbuatan yang menjijikkan bagi Tuhan dan menjadi momok yang menggelisahkan bagi orang itu sendiri. ${ }^{13}$ Oleh sebab itu, seksualitas yang kudus atau melakukan hubungan seks yang baik dan kudus ialah diberkati dan dikuduskan atau dipersatukan di dalam Tuhan. Pada dasarnya hubungan sepasang kekasih merupakan keinginan semua orang pada umumnya. Hubungan yang kudus adalah hubungan yang sesuai dengan apa yang Tuhan perintahkan, yaitu harus hidup kudus, sebab Allah adalah kudus. ${ }^{14}$

Melalui hubungan suami isteri, manusia dapat meneruskan anugerah kehidupan yang diberikan Allah. Dalam Perjanjian Lama penyebaran umat manusia merupakan sebuah berkat dari Allah. Dalam Perjanjian Lama tidak hanya membahas bagaimana tentang kekudusan seksual tersebut, Perjanjian Lama juga mencatat beberapa penyimpangan-penyimpangan seksual seperti dalam Kejadian 39:11-12 menggunakan kata shakab yang artinya berbaring dengan tujuan berhubungan seksual secara tanpa ikatan atau diberkati. Demikian juga halnya dalam Imamat 18:20 membahas pelencengan seksual dalam konteks seorang yang melakukan

\footnotetext{
12 Junius Halawa, "Seks Menurut Alkitab Sebagai Kontribusi Bagi Pengajaran Gereja Masa Kini," Scriptura Teologi dan Pelayanan Kontekstual 1 (2019): 174.

${ }^{13}$ Ibid. 175.

${ }^{14}$ Baran Rante Payung, "Katekisasi Pernikahan and Dalam Gereja," (n.d.) 2. 181 | Copyright@ 2021, CARAKA, ISSN 2722-1407 (Cetak), 2722-1393 (Online)
} 
hubungan seksual dengan orang yang belum diberkati dengan dirinya. Kemudian dalam Imamat 18:22 membahas pelencengan orientasi seksual. Terakhir, dalam Kejadian 19:34 membahas mengenai incest tentang pelanggaran seksual yang sama dengan beberapa contoh di atas yang sama menggunakan kata shakab atau berakar kata shakab yang dalam hal ini penggunaannya digunakan berdasarkan suatu hal yang dilakukan dengan berbohong atau yang salah (tidak diberkati oleh Allah) melanggar hukum Allah.

\section{Kekudusan Allah}

Kekudusan Allah adalah salah satu bagian dari sifat atau atribut yang ada pada diri Allah itu sendiri. Dalam Imamat 19:2 sangat jelas dikatakan “...: Kuduslah kamu, sebab Aku, TUHAN, Allahmu, kudus...." Berulang-ulang kali kata Akulah TUHAN disebutkan dalam Imamat 19, dengan artian bahwa Allah seakan-akan menuntut umat-Nya untuk melakukan segala sesuatu sesuai dengan keinginan-Nya seturut yang telah Ia lakukan. ${ }^{15}$ Bahkan dalam Imamat 11:44 mengatakan bahwa "sebab Akulah TUHAN, Allahmu, maka haruslah kamu menguduskan dirimu dan haruslah kamu kudus, sebab Aku ini kudus..." Hal ini perlu dipahami bahwa mengenai kekudusan Allah tidak akan terlepas kaitannya dengan umat yang telah dipilih-Nya. Allah tidak suka dengan kehidupan orang Israel yang selalu menyimpang dari apa yang Dia perintahkan. Allah menyatakan kekudusan-Nya melalui sikap dan perbuatan yang Ia lakukan untuk menyelamatkan umat-Nya. Seperti halnya pada waktu umat Israel di padang gurun dan mereka kehabisan air, mereka memberontak terhadap Musa dan Harun dan kepada Tuhan. Allah menunjukan kekudusan-Nya di antara para kaum Israel melalui tindakan yang TUHAN lakukan (Bil. 20:13). Kekudusan Allah menunjukkan perbedaan antara manusia dengan Allah. Hanya saja, kudus yang dimaksud tidaklah terlepas dari hubungan manusia dengan Allah. Sebab, dalam hubungan Allah dengan umat-Nya, Allah tampak sebagai Yang Kudus, yang tidak dapat bersekutu dengan dosa. Setiap umat yang ingin bersekutu dengan Allah, maka ia haruslah hidup dalam kekudusan. Melalui hidup yang kudus, umat dapat berkomunikasi dengan TUHAN. ${ }^{16}$ Allah itu kudus oleh karena itu kekudusan-Nya haruslah diteladani. Allah mau supaya setiap umat-Nya dapat menghormati kekudusan-Nya (Bil. 20:12). Allah menekankan kepada seluruh umat Tuhan untuk percaya bahwa Ia akan menuntun mereka ke tanah yang telah Tuhan janjikan. Oleh sebab itu, Allah selalu 2007), 25

${ }^{15}$ Christopher Wright, Hidup Sebagai Umat Allah: Etika Perjnajian Lama (Jakarta: Gunung Mulia,

${ }^{16}$ Prayitno, "Pemahaman Pembangunan Doktrin Kekudusan Allah Bagi Mahasiswa Teologi." 64-65 182 | Copyright $@$ 2021, CARAKA, ISSN 2722-1407 (Cetak), 2722-1393 (Online) 
mengingatkan bahwa Aku TUHAN adalah kudus, maka umat juga harus kudus sama seperti Allah yang hidup kudus dalam segala perbuatan-Nya.

Yesaya 6:1-7 juga memperlihatkan satu peristiwa di mana, nabi Yesaya melihat Tuhan yang bertahta dan memenuhi bait suci. Dalam Yesaya 6:3 diungkapkan bahwa "...: kudus, kudus, kuduslah Tuhan semesta alam, seluruh bumi penuh kemuliaan-Nya!" kata kudus diulang-ulang sebanyak tiga kali dalam ayat ini, kata yang diulang ini merupakan penekanan dan penegasan sesuatu hal yang penting. Di ayat berikutnya Yesaya berkata "celakalah aku! aku binasa! Sebab aku ini seorang yang najis bibir, namun mataku telah melihat Sang Raja, yakni TUHAN semesta alam.” (Yes. 6:5). Yesaya menunjukkan betapa kudusnya Allah itu sehingga ia berkata bahwa aku adalah seorang yang najis, namun aku melihat TUHAN yang adalah raja semesta alam. Kekudusan Allah berarti di dalam diri-Nya tidak terdapat kecemaran dan kebersalahan secara mutlak yang ditemukan dan bahkan kekudusan Allah pun tidak akan mungkin berubah dan tidak dapat tercemar oleh apapun. Sifat kekudusan-Nya, Allah tidak akan ceroboh dan salah dalam bertindak. Sebab Allah itu adil dan sempurna sehingga keputusan yang dilakukan oleh Allah selalu bertujuan baik untuk umat-Nya. ${ }^{17}$

Kudus menggambarkan transendensi Allah oleh karena kekudusan-Nya sangat bertentangan dengan ilah-ilah (Kel. 15:11) dan terhadap seluruh ciptaan-Nya (Yes. 40:25). Di lihat dari budaya dan kebiasaan Israel, bahwa setiap orang yang berbuat dosa dan melakukan penyembahan kepada ilah-ilah lain mereka harus menguduskan diri terlebih dahulu dengan mempersembahkan korban serta persembahan sebagai tanda pendamaian atas dosadosa mereka. Jadi, kekudusan Allah merupakan inti dari keberadaan-Nya, karena itu kekudusan Allah adalah pemisahan diri dari segala sesuatu yang menentang dan melawan Allah. Segala sesuatu yang baik adalah kehendak Allah dan yang jahat adalah bentuk penentangan dan melawan Allah. Edmond Jacob berpendapat bahwa Allah itu kudus, oleh karena itu Allah mengikat perjanjian dengan manusia dengan tujuan supaya manusia dapat menjadi kudus. Dalam Amos 4:2 Tuhan Allah bersumpah demi kekudusan-Nya itu dengan artian bahwa Allah bersumpah demi hakikat-Nya sendiri. ${ }^{18}$

\section{Kekudusan Seksualitas: Hubungan Manusia dengan Allah}

Kekudusan Allah menuntut kekudusan umatNya artinya umat Allah, yang adalah sekutu Allah juga harus hidup terpisah daripada segala dosa dan mempersembahkan seluruh 89.

${ }^{17}$ Herowati Sitorus, “Jemaat Yang Kudus Sebagai Reinterpretasi Kehadiran Allah” 1, no. 1 (2017): 88-

${ }^{18}$ Ibid. $95-96$

183 | Copyright@ 2021, CARAKA, ISSN 2722-1407 (Cetak), 2722-1393 (Online) 
hidup bagi Allah (Im. 19:2), tanpa hidup yang kudus tidak mungkin ada persekutuan dengan Allah yang kudus. Untuk itu, manusia sebagai ciptaan Allah harus hidup dalam kekudusan, dikhususkan umat Allah dapat dipahami dengan umat Israel, yang telah dibebaskan dari perbudakan Mesir, mereka harus hidup sesuai dengan kebiasaan baru yang terikat pada kehendak Allah yang kudus (Im. 19:2). Allah adalah kudus dan kekudusan Allah tidak berkompromi dengan dosa, karena itu umat Allah harus kudus. Seperti halnya dalam Kejadian 1:27-28, Allah memberkati manusia untuk bertambah banyak dan berkuasa atas ciptaan lainnya.

Ruth dan Freshia mengatakan bahwa perkawinan didasarkan pada daya tarik seksual antara laki-laki dan perempuan yang berasal dari karya dan kehendak pencipta (Allah). ${ }^{19}$ Graham Roberts mengatakan tujuan Allah melalui pernyataan ini, membimbing umatNya agar mengerti maksud pernikahan yang mulia menurut kehendakNya. Seperti yang terdapat dalam Kejadian 2:24 mengandung hikmat Allah untuk memahami bahwa dalam pernikahan manusia menikmati suatu pernikahan yang satu atau heterogen dalam hubungan suami dan isteri. ${ }^{20}$ Artinya dalam hubungan suami dan isteri tidak akan ada orang ketiga "poligami", yang juga mengarah kepada hubungan seksual laki-laki dan perempuan.

Dalam Kejadian 4:1, kata "bersetubuh" berasal dari kata ידע' (yada) dalam bahasa Ibrani yang artinya mengenal, intim, menasihati, berhubungan dan menikmati. Hal ini juga terdapat dalam Hosea 2:19, yang lebih mengarah kepada penyataan Allah atas KaruniaNya kepada orang pilihanNya. Dalam hal ini, oleh karena kasih karuniaNya manusia dijadikan pasangan Allah seperti suamiNya (dalam ayat 15) dan sebagai isteriNya (dalam ayat 18-19) membangun hubungan yang penuh keintiman seperti suami mengenal isteri dan isteri mengenal suami. Sehingga pernikahan merupakan hubungan yang sangat didambakan oleh Allah.

Dalam Yeremia 31:31-32 juga dituliskan bahwa Israel sendiri dibawa keluar dari Mesir dan kemudian mengadakan perjanjian dengan mereka, memasuki kepada hubungan yang baru lagi seperti suami dan isteri. Sehingga dalam Yeremia juga menunjukkan bahwa Israel murtad/tidak setia yaitu berpaling kepada penyembahan berhala. Sekalipun demikian, Allah tidak menolak Israel untuk selama-lamanya atas ketidaksetiaan mereka, Ia akan membuat lagi suatu perjanjian baru untuk menjadi pasangan (suami/isteri) Israel lagi. 2012), 146.

${ }^{19}$ Ruth Schafer Dan Freshia Aprilyn Ross, Bercerai Boleh Atau Tidak? (Jakarta: Bpk Gunung Mulia,

${ }^{20}$ Graham Roberts, Kawin Campur Dan Campur Tangan Tuhan (Jakarta: Yayasan Komunikasi Bina Kasih, 2007), 19-20.

184 | Copyright@ 2021, CARAKA, ISSN 2722-1407 (Cetak), 2722-1393 (Online) 
Harrold mengatakan bahwa Making love is as important to God as is making babies. Making love as a mode of human communication and a method of exploring each other's persons and personalities is an essentially biblical theme, leading to the biblical notion that two humans by sexual play become "one flesh," means that sex can bring about a profound connection at the deepest visceral level. Only in sexual union and in spiritual communion do we reach that profound, wholesome, and holy enmeshment. ${ }^{21}$ Dengan demikian, melalui seksual tersebut, setiap orang dapat mengalami keterikatan yang mendalam, sehat dan suci. Demikian dengan Allah, yang mana, Ia ingin umat memiliki keterkaitan yang erat dan mendalam dan kudus. Sehingga, umat Israel atau setiap manusia lebih dekat dengan Dia dan menjadi satu, seperti halnya manusia yang telah diberkati Tuhan dan dipersatukan menjadi satu daging.

Dalam Hosea 2:15 -19, di ayat sembilan belas, sangat dalam membahas mengenai kesetiaan Allah kepada Israel yaitu Allah akan menunangkan diriNya kembali sebagai bentuk kesetiaanNya atas Israel. Sehingga Israel akan mulai mengenal kembali Allah dengan berdasarkan komitmen atau janji antara Allah dan Israel. Mengenai hubungan Allah dengan Israel yang digambarkan dalam Perjanjian Lama, melalui Perjanjian yang diadakan dengan Israel di Gunung Sinai sebagai tanda pernikahan Israel dan Allah. ${ }^{22}$ Dalam kehidupan seharihari, Israel selalu menyimpang dan melakukan kejahatan di mata Tuhan. Umat Israel sudah menjadi umat Allah pada saat Allah membebaskan mereka dari perbudakan di Mesir.

Berkat tindakan Allah yang berkuasa, umat Israel menjadi bangsa yang merdeka, suatu persekutuan yang terdiri dari orang-orang yang merdeka. Allah telah membebaskan Israel dari rasa takut terhadap manusia menjadi percaya kepada-Nya. Ketika umat Israel menjadi umat Allah, hal itu berarti mereka mengabdi dan melayani sebagai hamba Allah. Tujuan Allah membebaskan mereka dari perbudakan di Mesir adalah supaya umat Israel dapat beribadah kepada Allah tanpa adanya halangan dan Allah tidak mau umat-Nya menjadi milik pihak lain. Umat Israel diperintahkan oleh Allah untuk beribadah hanya kepada Allah saja, karena Allah sudah membebaskan, menyelamatkan, menebus mereka.

Allah menghendaki umat Israel menjadi bangsa yang berbeda dengan bangsa-bangsa yang lain. Umat Israel diharapkan untuk menunjukkan iman mereka kepada Allah dengan ketaatan yang penuh rasa syukur, dan Allah telah menjanjikan kepada umat Israel bahwa

${ }^{21}$ J. Harold Ellens, Sex in the Bible : A New Consideration (United States Of America : Praeger Publisher, 2006), 52.

${ }^{22}$ Derek Prince, Pernikahan Ikatan Yang Kudus (Jakarta: Yayasan Pekabaran Injil Immanuel, 1992), 7173.

185 | Copyright $\odot$ 2021, CARAKA, ISSN 2722-1407 (Cetak), 2722-1393 (Online) 
kepatuhan kepada hukum-hukum Allah akan menjamin keberhasilan mereka (Ul. 6:3) serta hidup dalam kekudusan dan tidak melakukan penyembahan kepada para baal. ${ }^{23}$ Bahkan, sebelum orang Israel memasuki tanah perjanjian, Allah telah memperingati mereka agar tidak menyembah kepada dewa-dewa negeri orang Kanaan (Ul. 6:14-15), namun umat Israel keras kepala dan tidak mau mengindahkan perintah Tuhan. Allah mengasihi seluruh umat-Nya, sehingga Tuhan selalu mengingatkan mereka untuk tidak berpaling daripada-Nya. ${ }^{24}$

Hubungan yang diinginkan Allah dengan Israel ialah haruslah bagaikan suami dengan isteri yang sedang melakukan hubungan seks. Melalui hubungan seks tersebut, suami-isteri dapat saling mengenal satu dengan yang lain dan bisa lebih dekat. Kata yada adalah kata yang digunakan dengan pengertian bersetubuh, dalam artian sepasang suami-isteri yang saling menikmati pada saat berhubungan intim. Hubungan yang diinginkan Allah yaitu umat Israel harus yada terhadap Dia atau bersetubuh atau berhubungan intim dengan Tuhan seperti halnya suami-isteri dimana manusia dapat menikmati hubungan dengan Allah begitupun sebaliknya.

Saat manusia dipersatukan dengan Allah, Ia memberkati manusia seperti halnya perkawinan, disana Allah menggambarkan bahwa seksualitas merupakan anugerah atau bentuk KasihNya pada manusia yang sangat kudus dan harus dinikmati secara heterogen, dan hubungan manusia juga begitu dalam Hosea pasal 2, dimana Allah terus menantikan hubungan yang kudus dengan manusia seperti manusia menjaga kudusnya perkawinan seperti dalam Imamat. Allah yang kudus sudah menggambarkan bagaimana Ia menciptakan manusia segambar dan serupa denganNya, manusia harus menjaga hati dan diri sebagai bentuk kekudusan yang Allah inginkan.

\section{KESIMPULAN}

Allah yang kudus menghendaki umat yang kudus pula. Allah senantiasa menginginkan hubungan yang baik dengan umatNya, sama halnya seperti dalam hubungan seksual antara suami dan isteri. Melalui penelitian ini, setiap orang dapat diingatkan bahwa kekudusan seksual sangatlah penting, sebab dalam hubungan seksual menggambarkan adanya suatu keterikatan atau sebuah perjanjian. Hubungan seksualitas haruslah kudus dan berkenan di hadapan Tuhan, demikian juga kita dalam berhubungan dengan Allah, yaitu hidup kudus dan benar dihadapan-Nya.

25 .

${ }^{23}$ Robi Prianto, “Tradisi Pemberian Kanaan Dan Pemilihan Dalam Kepercayaan Israel,” Te Deum (n.d.):

\footnotetext{
${ }^{24}$ Wibowo, "Asimilasi dan Akulturasi Penyembahan Baal di Bangsa Israel: Pendekatan Sosio Teologis Menurut Teori Multi Stage Asssimilation Milton M. Gordon", 6.
}

186 | Copyright $\odot$ 2021, CARAKA, ISSN 2722-1407 (Cetak), 2722-1393 (Online) 


\section{DAFTAR PUSTAKA}

Berkhof, Louis. Teologi Sistematika Jilid 4. Surabaya: Momentum, 2001.

Ellens, J. Harold. Sex in the Bible : A New Consideration. United States of America: Praeger Publisher, 2006.

Halawa, Junius. "Seks Menurut Alkitab Sebagai Kontribusi Bagi Pengajaran Gereja Masa Kini." Scriptura Teologi dan Pelayanan Kontekstual 1 (2019): 174.

Lasor W.S., Dkk. Pengantar Perjanjian Lama 1. Jakarta: Bpk Gunung Mulia, 2008.

Natar, Asnath N. "Perempuan Dalam Kitab Hosea" (n.d.).

Pernikahan, Katekisasi, and Dalam Gereja. "Baran Rante Payung" (n.d.).

Prayitno, Agus. "Pemahaman Pembangunan Doktrin Kekudusan Allah Bagi Mahasiswa Teologi" (2011): 7.

Prianto, Robi. "Tradisi Pemberian Kanaan Dan Pemilihan Dalam Kepercayaan Israel." Te Deum (n.d.): 247-261.

Prince, Derek. Pernikahan Ikatan Yang Kudus. Jakarta: Yayasan Pekabaran Injil Immanuel, 1992.

Roberts, Graham. Kawin Campur Dan Campur Tangan Tuhan. Jakarta: Yayasan Komunikasi Bina Kasih, 2007.

Ross, Ruth Schafer dan Freshia Aprilyn. Bercerai Boleh Atau Tidak? Jakarta: Bpk Gunung Mulia, 2012.

Setiadi, Made Nopa. Immorality : Sebuah Studi Biblika-Sistematis. Bengkulu: Permata Raflesia, 2020.

Sitorus, Herowati. "Jemaat Yang Kudus Sebagai Reinterpretasi Kehadiran Allah" 1, no. 1 (2017): 85-100.

Suwarni, Linda. "Hubungan Antara Lovestyle, Sexsual Attitudes, Gender Attitudes Dengan Perilaku Seks Pra-Nikah,” no. 111 (2012): 1-11.

Wibowo, Gandi. "Asimilasi Dan Akulturasi Penyembahan Baal Di Bangsa Israel: Pendekatan Sosio Teologis Menurut Teori Multi Stage Asssimilation Milton M. Gordon." Voice 1, no. 1 (2021): 18-30.

Wright, Christopher. Hidup Sebagai Umat Allah: Etika Perjnajian Lama. Jakarta: Gunung Mulia, 2007.

Yaniawati, Poppy. "Penelitian Studi Kepustakaan.” Penelitian Kepustakaan (Liberary Research), no. April (2020): 15. 